\section{Difetarsone in outpatient treatment of Trichuris trichiura infestation}

Dysentery due to infestation with the whipworm, Trichuris trichiura, is common among underprivileged children living in Cape Town. Chronic blood loss and a diet deficient in iron leads to profound anaemia and it is not unusual for young children with this infestation to present in cardiac failure. While temporary correction of anaemia and treatment of iron deficiency are readily achieved, eradication of the worm from the colon (Fig.), whether by means of enema or drug therapy, has hitherto not been satisfactorily achieved. After the report by Lynch et al. (1972), a controlled study was undertaken of the effect of difetarsone on the Trichuris dysentery of outpatients who attended the Red Cross War Memorial Hospital. Findings are reported in this paper.

\section{Methods}

Warm stool specimens were routinely examined in the laboratory from all children who presented at the outpatient department with a history of chronic diarrhoea or dysentery. When ova of Trichuris were shown on microscopy, an accurate egg count was carried out on $0.5 \mathrm{~g}$ faeces, using the formol-ether concentration technique described by Allen and Ridley (1970). The slide preparation was microscopically examined with a magnification of 10 . It was calculated that at this magnification the entire area under a standard coverslip occupied 289 microscopical fields. Using a consistent pattern of field selection, a total count was made of all the eggs in 9 fields. An average was obtained by division and this figure was then multiplied by 289 to obtain the total number of eggs in all the microscopical fields on the slide. This final number was doubled so that the result could be expressed per $\mathrm{g}$ faeces.

After the initial count patients with Trichuris infestation were allocated at random to one of 2 groups, $A$ and $B$. The mothers of patients in group $A$ were instructed to give the children a single daily dose of difetarsone on each of the following 5 days. The daily dose was calculated at $50 \mathrm{mg} / \mathrm{kg}$ per day and the exact number of tablets was supplied for the 5-day course. The mothers of children in group B were given similar instructions but in place of difetarsone were supplied with ascorbic acid tablets. The mothers in both groups were instructed to bring the children back to the

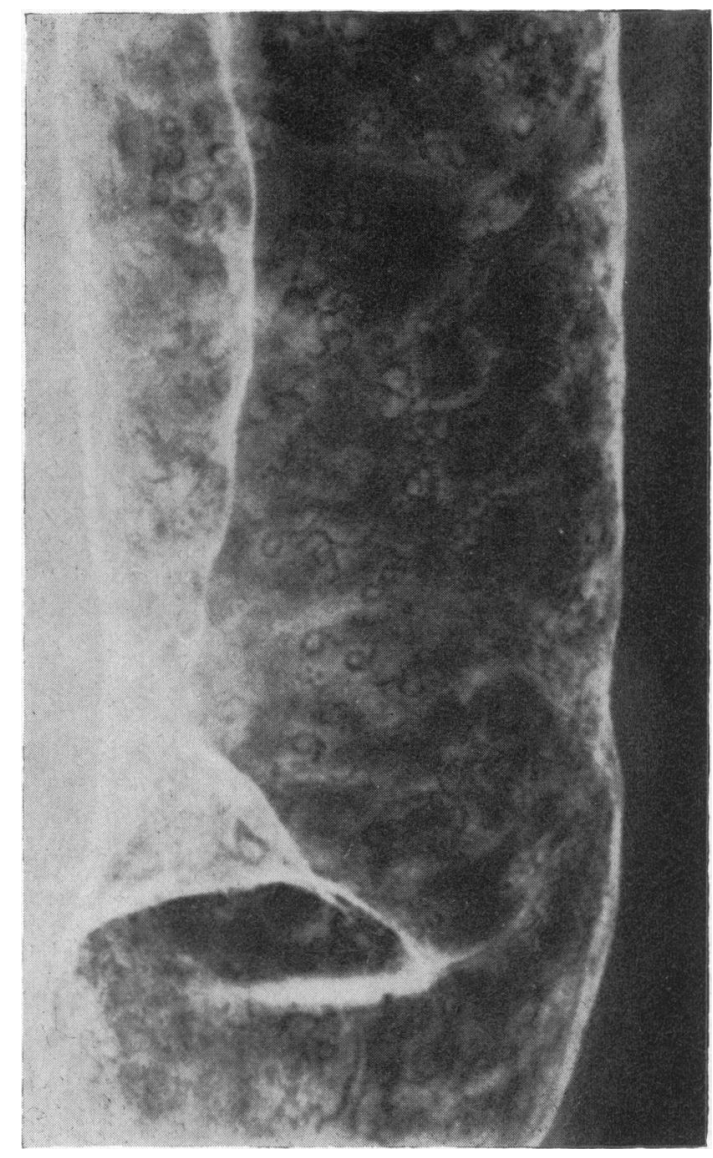

FIG.-X-ray of colon after barium enema examination showing heavy infestation with Trichuris trichiura

outpatient department 14 days after the issue of tablets. At this visit a note was made of symptoms and a further stool specimen was obtained. A third stool was obtained 28 days after the start of treatment. Both of these stool specimens were submitted for Trichuris ova counts. All egg counts were carried out by the same individual (S.T.B.) who did not know to which group any given child had been allocated.

\section{Results}

There were 44 children in group A (difetarsone). The mean age was $3 \cdot 7$ years, range 1 to 11 years. In 17 the weight was below the 3rd Boston centile 
for age. 31 of the 44 presented for the second stool specimen collection exactly 14 days after the start of treatment. The rest returned after intervals ranging from 12 to 35 days. 24 of the group presented exactly 28 days after the start of treatment for the third specimen collection. The remainder returned between 26 and 50 days after the first day of treatment. Thus, on average the second stool specimen was examined about 16 days after start of treatment and the third specimen was examined approximately 32 days after start of treatment.

There were 19 children in group B (ascorbic acid). The mean age was 3.8 years, range 1 to 12 years. 5 had weights below the 3rd Boston centile for age. The second stool specimen was obtained on average 14 days after starting placebo treatment (range 13 to 15 days), and the third stool specimen on average 30 days after treatment had started (range 22 to 53 days).

The initial mean egg count in group A was 4211 eggs/g faeces, range 36 to 19,830 . The mean count in group B was $3500 \mathrm{eggs} / \mathrm{g}$ (range 58 to 17,880 ). In Table I the individual counts both before and after

TABLE I

Comparison between initial and subsequent faecal egg counts in those who received difetarsone (group $A)$ and those who received placebo (group $B$ )

\begin{tabular}{l|c|c|c}
\hline \multicolumn{1}{c|}{ Ova/g faeces } & Initial stool & 2nd stool & 3rd stool \\
\hline $\begin{array}{l}\text { Group } A \text { (treated) } \\
\text { (no. }=44 \text { ) }\end{array}$ & & & \\
Nil & 0 & 16 & 24 \\
$<100$ & 3 & 6 & 5 \\
$100-1000$ & 11 & 15 & 12 \\
$1000-5000$ & 23 & 4 & 2 \\
$>5000$ & 7 & 3 & 1 \\
Group B (controls) & & & \\
(no. $=19$ ) & 0 & 0 & 0 \\
Nil & 1 & 0 & 0 \\
$<100$ & 5 & 6 & 3 \\
$100-1000$ & 10 & 9 & 13 \\
$1000-9000$ & 3 & 4 & 3 \\
$>9000$ & & & \\
& & & \\
\hline
\end{tabular}

treatment have been arranged in numerical categories, showing that $\mathbf{2 4}$ in group A were free of ova 2 weeks after treatment, and all but 3 had less than 1000 ova per $g$ faeces. A number of children in group B showed an increase in egg counts and at 2 weeks only 3 had fewer than 1000 ova per $g$.

For comparison, second and third egg counts were calculated as percentages of the initial count in each case. It was thus possible to calculate the percentage reduction in the egg count. Groups A and $B$ have been compared in this way and it is clear from Table II that 1 month after treatment 37 of the 44 children treated with difetarsone had very considerable reductions in egg excretion, while none of the children treated with a placebo showed marked change.

No side effects were reported or observed in any of the children treated with difetarsone. The mothers of children in group A reported a marked decrease in stool frequency and dysentery, while those in group B reported no improvement or a worsening of symptoms.

\section{Discussion}

The whipworm Trichuris trichiura is responsible for much morbidity in the underprivileged children of the Western Cape area. Infestation is a common finding in toddlers suffering from kwashiorkor and serves to aggravate both the diarrhoea and anaemia which occur in that condition. Reports of infestation have come from many tropical regions and the combination of a moist hot climate and primitive sanitary arrangements favour the worms' survival (Hunter, Frye, and Swartzwelder, 1966). A recent report indicates that even in temperate climates infestation may be widespread among children living in institutions (Lynch et al., 1972).

The outpatient department of the Red Cross Children's Hospital handles approximately 230,000 patients per year. Because of a shortage of beds, only those children who are seriously ill can be

Change in faecal egg counts expressed as percentages of initial count

\begin{tabular}{|c|c|c|c|c|}
\hline \multirow[t]{2}{*}{ - } & \multicolumn{2}{|c|}{ 2nd stool examination } & \multicolumn{2}{|c|}{ 3rd stool examination } \\
\hline & $\begin{array}{c}\text { Group A } \\
\text { (treated) } \\
(\text { no. }=44)\end{array}$ & $\begin{array}{c}\text { Group B } \\
\text { (controls) } \\
(\text { no. = 19) }\end{array}$ & $\begin{array}{c}\text { Group A } \\
\text { (treated) } \\
\text { (no. }=44)\end{array}$ & $\begin{array}{c}\text { Group B } \\
\text { (controls) } \\
\text { (no. = 19) }\end{array}$ \\
\hline $\begin{array}{l}\text { No ova } \\
\text { Reduction } 95 \% \\
\text { Reduction } 85 \% \\
\text { Reduction }>50 \% \\
\text { Reduction }<50 \% \\
\text { Increase or no change }\end{array}$ & $\begin{array}{r}16 \\
9 \\
6 \\
6 \\
2 \\
5\end{array}$ & $\begin{array}{r}0 \\
0 \\
1 \\
3 \\
4 \\
11\end{array}$ & $\begin{array}{r}24 \\
8 \\
5 \\
2 \\
4 \\
1\end{array}$ & $\begin{array}{r}0 \\
0 \\
0 \\
5 \\
3 \\
11\end{array}$ \\
\hline
\end{tabular}


admitted to hospital wards and the vast majority must be treated as outpatients. Similar conditions prevail in other developing countries and it was with this fact in mind that the present study was undertaken on outpatients. There can be no certainty that every child in fact received his tablets according to the instructions given. However, the striking difference in subsequent egg counts between those treated with difetarsone and those who received placebo shows the effectiveness of the drug, and when consideration is given to the findings in other studies (Junod, 1965; Garin et al., 1970; Nitzulescu et al., 1970; Lynch et al., 1972; Rubidge, O'Dowd, and Powell, 1973) we suggest that in those cases in group A with a small reduction in egg count dosage instructions were not followed. Further confirmation of the efficacy of difetarsone was provided by the considerable persuasion necessary to induce many of the mothers in group A to bring their children back to hospital for second and third stool collections. The invariable explanation offered for failure to keep an appointment was that the child had fully recovered and that further attendance at hospital was not thought necessary. This was in marked contrast to the prompt and sometimes premature return of children in group B who still had severe diarrhoea.

\section{Conclusion}

The present study has confirmed the value of difetarsone in the treatment of Trichuris infestation, and has shown that a single dose administered daily for 5 days is sufficient to eliminate even heavy worm loads. Side effects have not been encountered. When consideration is given to the morbidity caused by Trichuris infestation, its worldwide distribution, and the ineffectiveness of other preparations which have been tried, the advent of difetarsone represents a significant contribution to the treatment of the condition.

\section{Summary}

A controlled study was carried out to test the effectiveness of difetarsone in the outpatient treatment of children suffering from dysentery due to infestation with the whipworm Trichuris trichiura. This drug was effective in curing an infestation which has hitherto been very resistant to treatment.

We are grateful to Dr. D. McKenzie for the use of laboratory facilities and to Maybaker (S.A.) (Pty) Ltd. for supplies of difetarsone. The Fig. was from a barium enema examination carried out by Dr. R. Fisher. The Medical Superintendent of the Red Cross War Memorial Children's Hospital gave permission to publish.
REF.JRENCES

Allen, A. V. H., and Ridley, D. S. (1970). Further observations on the formol-ether concentration technique for faecal parasites. fournal of Clinical Pathology, 23, 545.

Garin, J. P., Despeignes, J., Woehrle, R., and Ambroise-Thomas, P. (1970). La diphétarsone, médicament actuel de la trichocéphalose. Bulletin de la Société de Pathologie Exotique et de Ses Filiales, 63, 94.

Hunter, G. W., Frye, W. W., and Swartzwelder, J. C. (1966). A Manual of Tropical Medicine, 4th ed., p. 874. Saunders, Philadelphia and London.

Junod, C. (1965). Essai de traitement de la trichocéphalose par la diphétarsone. Bulletin de la Société de Pathologie Exotique et de Ses Filiales, 58, 653.

Lynch, D. M., Green, E. A., McFadzean, J. A., and Pugh, I. M. (1972). Trichuris trichiura infestation in the United Kingdom and treatment with difetarsone. British Medical fournal, 4, 73.

Nitzulescu, V., Simionescu, O., Lucian, O., Corijescu, V., Brinzei, A., and Juvara, A. M. (1970). Le traitement de la trichocéphalose par le Bémarsal. Bulletin de la Société de Pathologie Exotique et de Ses Filiales, 63, 251.

Rubidge, C. J., O'Dowd, P. B., and Powell, S. J. (1973). Difetarsone in the treatment of Trichuris trichiura infections. South African Medical fournal, 47, 991.

P. M. Leary, ${ }^{\star}$ Christine Jones, Felicity Douglas, and S. T. BOYD

Department of Paediatrics and Child Health, University of Cape Town and Red Cross War Memorial Children's Hospital, Cape Town, South Africa.

^Correspondence to Dr. P. M. Leary, Department of Paediatrics and Child Health, University of Cape Town Medical School, Observatory, Cape, South Africa.

\section{Pentazocine (Fortral) as post- operative analgesic in children}

Pentazocine (Fortral) has been shown to be a powerful analgesic in adults (Ende, 1965). Its use in postoperative children was discussed by Gaines (1967), who found it effective in 42 out of 51 children studied while producing minimal side effects. McSwan et al. (1966) described a double-blind study involving pentazocine which included 12 children undergoing heart surgery, and found it effective in this condition. The aim of this paper is to extend these observations on pentazocine by describing an open assessment comparison with nepenthe and a double-blind comparison with pethidine.

\section{Patients.}

\section{Methods}

Trial $A$ (age 1-4 years). 10 patients aged 1 to 4 years were studied after inguinal herniotomy, circumcision, orchidopexy, appendicectomy, or biopsy of sacral teratoma, 5 children being given each treatment. Nepenthe was injected using the dosage formula, 0.06 $\mathrm{ml} \times$ age $(\mathrm{yr})$, with an additional 0.6 or $1.2 \mathrm{ml}$ given for 